\title{
Letters
}

\section{Obstacles to health in the Arab world}

EdIToR-Health indicators in the Arab world show stark differences between individual countries. But aggregate figures provide only a narrow perspective. They do not show variation according to socioeconomic group, sex, education, or political affiliation. The scarcity of databases available to collect such detailed data reflects the fact that inadequate political support exists for rigorous intersectoral research of relevance for health in the region. National development agendas and public policies are focused on economic development. Funding for health tends largely to be directed at providing curative medical services designed to emulate Western health systems. ${ }^{1}$

Patriarchal and religious principles embedded in the state structures of many Arab countries-such as Lebanon, Egypt, and Saudi Arabia-are a further obstacle to unpicking and taking action to tackle poor health and health inequity in the region. The conservative values of the Arab world render public debates about religion, politics, and sexuality unacceptable and place social stigma around drug users, commercial sex workers, and mentally ill people. As a result, health data on such groups are limited and unreliable, ${ }^{2}$ which presents an obstacle for the development of appropriate services.

Although national cultural, social, and economic structures are to blame for patchy and inequitable public health services, particularly in Egypt, Morocco, and Lebanon, ${ }^{3}$ regional and global forces influence health provision too. The Arab-Israeli conflict, the wars in Iraq, the Gulf, Lebanon, Yemen, and Sudan have brought about hunger, epidemics, displacement, and death. These wars have been tacitly bolstered by multinational corporations, which have sold billions of dollars worth of weapons to Arab countries in conflict. Governments' expenditures on defence in some Arab countries are greater than their expenditure on health. ${ }^{4}$ International political action (and inaction), notably in Iraq and Lebanon, has played a part too. Similarly, global decisions have led to fluctuations of funding for the United Nations Relief and Works Agency (UNRWA), the leading health and social service provider to Palestinian refugees. ${ }^{5}$

Multilateral and bilateral aid has also influenced public policy making in many economies of the Arab world, owing to demands for reform and reduced public sector spending. These have had a dispro- portionate effect on low income groups. Although several Arab countries have banned tobacco advertisements, tobacco companies continue to reach Arab homes through satellite television stations, another global feature. Tobacco related mortality is expected to reach 0.5 million deaths in the Arab world by 2020 .

Further investigation of the ways that powerful regional and global agents effect health in the Arab world and beyond is crucial for a clearer perspective on obstacles to health. Only then will the possibility of advocacy for lasting health see the light.

\section{J Makhoul associate professor}

jm04@aub.edu.lb

F El-Barbir public health practitioner

Department of Health Behaviour and Education, Faculty of Health Sciences, American University of Beirut, PO Box 11-0236, Riad el Solh 1107-2020, Beirut, Lebanon

Competing interests: None declared.

1 United Nations Development Programme (UNDP), Arab Fund for Economic and Social Development, Arab Gulf Programme for United Nations Development Organizations. Arab human development report 2004 towards freedom in the Arab World. New York: UNDP, 2004.

2 Economic and Social Commission for Western Asia (ESCWA). Selected social trends in the ESCWA region. New York: United Nations, 1997.

3 Makhoul J, Harrison LJ. Intercessory wasta and village development in Lebanon. Arab Studies Quarterly 2004:26(3):25-41.

4 Stork J. The Middle East arm bazaar after the cold war. Middle East Report 1995;197:14-9.

5 Brynen R. Donor contributions to UNRWA. In: Babille M, Barney I, Brynen R, Jacobsen LB, Endersen L, Hasselknippe G, eds. Social service delivery to Palestinian refugees: UNRWA and other provider, UNRWA financial and donor environment. Vol 3 of Finding means [CD-ROM]. Fafo report. 2003157-178.

\section{Reforming Egypt's health system: is it that simple?}

Editor-Egypt has witnessed several health gains during the past decades. Life expectancy at birth is increasing, $95 \%$ of the population has access to primary health care within $5 \mathrm{~km}$, and immunisation coverage is about $98 \%$. However, the quality of public health services is questionable and about $60 \%$ of expenditure on health is out of the patients' pockets. ${ }^{1}$ According to the World Health Organization, Egypt spends about $5.8 \%$ of its gross domestic product on health. ${ }^{2}$ This is lower than the countries in the Organisation for Economic Cooperation and Development (OECD)-which Egypt wants to join-which spend around

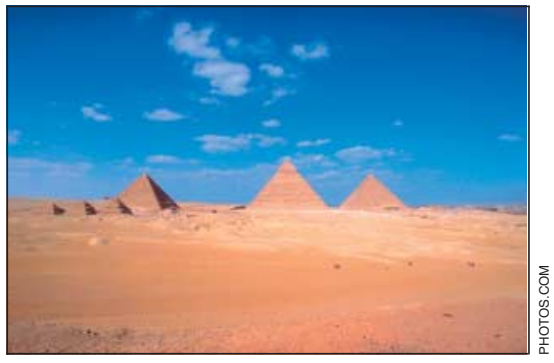

$8 \%$ of their gross domestic product on health. In 2000 the African countries, including Egypt, committed themselves to increasing health expenditure to $15 \%$ of gross domestic product by 2015 (Abuja Declaration $^{3}$ ). To date, Egypt's steps to increase budgetary allocation for health are not clear. Egypt's current government is examining ways to improve health services, including the expansion of social health insurance, and the question is how best to do this.

It is important to identify the main health and system challenges. Egypt, like many other countries in the region, is facing several new health challenges. Vulnerability to global health threats such as bird flu is increasing. The HIV infection rate in the Middle East and North Africa is rising rapidly. Two countries bordering Egypt (Libya and Sudan) have two of the highest rates of new infections in the region. The burden of non-communicable diseases in Egypt is increasing. Ironically, Egypt also faces challenges resulting from the improvements in its health system. The World Bank estimates that developing countries might face $2 \%$ annual increases in healthcare expenditure needs from the ageing of their populations.

The main challenge for the health system is the lack of capacity of the different stakeholders, which is mainly, but not exclusively, linked to financial problems. With low wages, poor training in managerial skills, and few incentives for change, it is difficult for the Ministry of Health to create change. As the private sector is an important stakeholder in health it is mandatory to create a more competitive environment. The World Bank has identified principles for sound public financing for health that involve raising revenue to provide basic essential services and pooling health risks equitably. However, issues such as taxation policy, budgetary allocation, and formalising the parallel economy make these remedies more difficult to realise. 
Furthermore, health is strongly affected by the performance of other sectors: safe water, sanitation, electricity, transportation, and education directly affect health.

Ultimately, civil society has an important role and has to act as a watchdog to protect the best interests of patients. Finally, good governance (with several reforms under way) will be a cornerstone of health reforms.

Wael Fayek Saleh health specialist African Development Bank, Temporary Reallocation Agency, Avenue du Ghana, BP 323-1002, Belvedere, Tunis, Tunisia w.saleh@afdb.org

Competing interests: None declared.

1 World Health Organization. World health report 2005-make every mother and child count. Geneva: WHO, 2005.

2 Regional Office for the East Mediterranean, World Health Organization. Egypt country profile. www.emro.who.int emrinfo/index.asp?Ctry = egy (accessed 1 Jun 2006).

3 Abuja Declaration and Framework for Action for the Fight Against HIV/ AIDS, Tuberculosis and other Related Infectious Diseases in Africa, 27 April 2001.

\section{Road traffic deaths in the Middle East: call for action}

EDITOR-One of the leading causes of death and disability in the Middle East is road traffic injuries. The World Health Organization estimates that by 2020 road traffic injuries will be the third leading cause of disability adjusted years of life lost worldwide. ${ }^{1}$ Our analysis of the International Road Federation's world road statistics found that five countries in the Middle East are among the highest road traffic death rates in the world. ${ }^{2}$ The table shows that the United Arab Emirates, Oman, Saudi Arabia, Qatar, and Kuwait all had more than 18 deaths per 100000 people in 2000.

Despite the seriousness of this problem, the full impact-morbidity, mortality, and disability-of road traffic injury in the Middle East is inadequately measured.

Death rates from road traffic injuries for countries in the Middle East by income ${ }^{2}$

Income and country Deaths per 100000 people

\begin{tabular}{lc}
\hline Low: & \\
\hline Yemen & 8 \\
\hline Lower middle*: & 13 \\
\hline Egypt & 8 \\
\hline Iraq & 15 \\
\hline Jordan & 10 \\
\hline Syria & \\
\hline Upper middlet: & 25 \\
\hline Oman & \\
\hline High: & 12 \\
\hline Bahrain & 8 \\
\hline Israel & 18 \\
\hline Kuwait & 19 \\
\hline Qatar & 21 \\
\hline Saudi Arabia & 29
\end{tabular}

${ }^{*}$ International Road Federation found only 4 deaths per 100 000 people in Iran but two independent studies found 23-24 deaths per 100000 in Iran. ${ }^{2}$ Turkey was omitted because World Bank gives rate $50 \%$ higher than International Road Federation. ${ }^{3}$

†No data available for Lebanon.
Bahrain and Israel are the only countries in the Middle East to have reported road traffic injury deaths by age to WHO. ${ }^{4}$ Although it has the lowest rates in the region, Bahrain has twice the road death rates of two other city states: Hong Kong and Singapore. ${ }^{2}$ Calculations based on data from WHO's statistical information system found that in Bahrain, more years of potential life are lost from injury than from heart disease, cancer, and infection combined. ${ }^{3}$

Death rates are higher in countries with more cars per 100000 people. $^{2}$ As the countries of the Middle East motorise, their death rates will inevitably rise. Investigators in Middle Eastern countries should identify interventions to lower the death toll from traffic fatalities. ${ }^{5}$ Above all, public health officials, road traffic designers, legislators, and the police should implement proved effective measures to lower the terrible tol of motor vehicle fatalities in the Middle East.

Emily Christensen-Rand $M P H, M B A$ candidate echriste@jhsph.edu

Adnan A Hyder assistant professor, Department of Adternational Health

Timothy Baker professor, Department of International Health

Johns Hopkins Bloomberg School of Public Health, 615 N Wolfe Street, Suite E-8132, Baltimore, MD 21205 , USA

Competing interests: None declared.

1 Murray C, Lopez A. The global burden of disease Murray C, Lopez A. The global burden of disease.
Cambridge: Harvard University Press/WHO/World Bank, 1996.

1996.
2 International Road Federation. World road statistics 2005. Geneva. IRF, 2005 .

3 Blomberg S. Road traffic safety in the Europe and central Asia regiom. Washington, DC: World Bank, 1999.

region. Washington, DC. World Bank, 1999. World Health Organization Statistical Information Sys 2006. www.who.int/whosis/en/ (accessed 1 Jul 2006). , Peden M, Mohan D, Hyder A, Jarawan $\mathrm{E}$, et al. World report on road traffic injuries prevention. Geneva: World Health Organization, 2004.

\section{Cancer prevention and control in Eastern Mediterranean region}

EditoR-In the Eastern Mediterranean region (population 492 million) cancer is the fourth most common killer with about half a million new cases a year. ${ }^{2}$ Lung, liver, and bladder cancer are commonest among men and breast cancer among women, the highest rates among Jewish women. ${ }^{3}$

World Health Organization modelling shows that over the next 15 years the increase in cancer incidence in the region will outstrip that in any other region (figure).

Reliable data on cancer incidence through national, population based registries are available in only seven of the 22 countries, and few governments have implemented prevention and control strategies. This failure is less to do with scant resources than a lack of political will and support for the development of appropriate services. Only minimal regulation is in place to protect workers from carcinogens, promote tobacco control, and expand hepatitis B programmes. $^{5}$ Public pressure for these

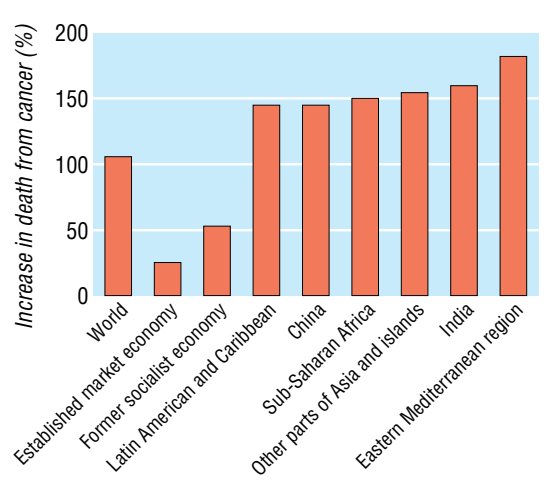

Predicted increase in deaths from cancer over the next 15 years $(\mathrm{WHO})^{4}$

services is low, and patients still tend to present late, with advanced disease. Well off and well educated people seek treatment abroad.

Awareness and concern are, however, growing in all sectors of society and among health professionals about the link between environmental damage from prolonged military conflicts and rising cancer rates. Oil pollution in Kuwait and Lebanon, chemical contamination in Iraq and Sudan, and depleted uranium in Iraq, Afghanistan, and Somalia have fuelled this concern.

Governments must take public concerns about cancer seriously. The collection and recording of sound data are essential, and cancer registries must align with international standards. Funding for national plans for cancer prevention and control must be made available. WHO's STEPwise programme should act as a guiding principle for developing these plans (www.who.int/ chp/steps/en/).

Patient and public input is important in shaping new services. Supraregional services may be needed to ensure access to some forms of specialist care-for example, bone marrow transplants, liver units. Some collaborative work is already under way in the Gulf Cooperation Council countries. Reorientation of services away from their current heavy emphasis on private sector provision of secondary care services to one that provides equitable primary care and preventive medicine services is crucial. ${ }^{5}$ Without such reorientation, cancer statistics will continue to rise, and the burden of what in a third of cases is a preventable disease will steadily increase.

Salman Rawaf director of public health salman.rawaf@swlondon.nhs.uk

Elizabeth Dubois public health economist

Wandsworth Primary Care Trust,

London SW17 7DG

Oussama M N Khatib regional adviser for non-communicable diseases

World Health Organization, Eastern Mediterranean Region, Cairo, Egypt

Sherif Omar professor of surgical oncology

National Cancer Institute, University of Cairo,

Cairo

Competing interests: None declared.

1 Gulf Center for Cancer Registration (GCCR). Cancer incidence 2000. Riyadh: GCCR, 2001. 
2 Mohagheghi M, Mosavi-Jarrahi A. Third annual report of the Tehran metropolitan area cancer registry. Tehran: Cancer
Institute Research Center, 2002. (Publication No 14.)

3 Partion Research Center, 200. (Tublication No 14.) arkin DM, Whelan SL, Ferlay J, Teppo L, Thomas DB, eds. Cancer incidence in five continents. Vol VIII. Lyons: International Agency for Research Rastogi T, Hildesheim A, Sinha R. Opportunities for cancer epidemiology in developing countries. Natur Reviews Cancer 2004;4:904-17.

Rear NeNA North Africa. Washington, DC: World Bank, 2004.

\section{Relation between mental health care and general development}

EDITOR-Disparities remain worldwide between high and low income countries in mental health services and protection of human rights for mentally ill patients. ${ }^{1}$ Substantial improvement has not been achieved in mental health since 2001, regional imbalances also remaining similar. ${ }^{2}$ When does society give importance to disadvantaged people? Can society be expected to protect the human rights of mentally ill people, irrespective of the state coming together as a functioning unit?

Two sets of data illustrate the relation between the development of the state and society and the country's commitment to mental health. The first is the failed states index ${ }^{3}$ and the second the availability of mental health staff in different countries. ${ }^{2}$

We examined the 15 countries of the WHO eastern Mediterranean region included in the failed states index and found a correlation with mental health staff. Lebanon and Morocco are the two notable exceptions. For the remaining countries, their position in the failed states index is similar to that for mental health staff. The five eastern Mediterranean countries with the highest position in the failed states index (Sudan, 3; Iraq, 4; Somalia, 5; Yemen, 8, Afghanistan, 11) had the smallest numbers of mental health staff.

The results show that when a state and society are struggling to keep their integrity, mental health is not a priority. Realistic strategies from mental health advocates are needed to develop mental health services in such countries. A need also exists to develop reliable mental health indicators to help monitor the development of mental health services and foster debate and research on mental health.

\section{Alex Souter volunteer}

R Srinivasa Murthy medical officer, mental health murthys_srinivasar@yahoo.co.in

Ahmad Mohit ex-director, health protection and promotion

World Health Organization, Eastern Mediterranean Region, Cairo, Egypt

Competing interests: None declared.

1 United Nations General Assembly Resolution 46/119 Principles for the protection of persons with mental illness and the improvement of mental health care. New York. UN, 1991. Gord Health Organizat Geneva: WHO, 2005

Feace. Failed state index 2005. www.fundforpeace.org/programs/fsi/fsindex2005.php (accessed 3 Oct 2006)

\section{Cause of death of Sri Lankan migrant workers employed in the Middle East}

EDITOR-With the introduction of the free trade policy, avenues have been opened for blue collar workers to obtain employment in the Middle East. The required funds to get to the destinations are often obtained through loans, workers mortgaging their few assets in anticipation of improving their living standards. From time to time, however, the harassment inflicted on these workers, often leading to disability and death, is reported in the print and the electronic media. ${ }^{1-5}$

A descriptive study was carried out to determine the cause of death as indicated on the death certificates received with the remains of Middle East migrant workers between 1 January and 31 May 2002 at the Health Office of the International Airport, Sri Lanka.

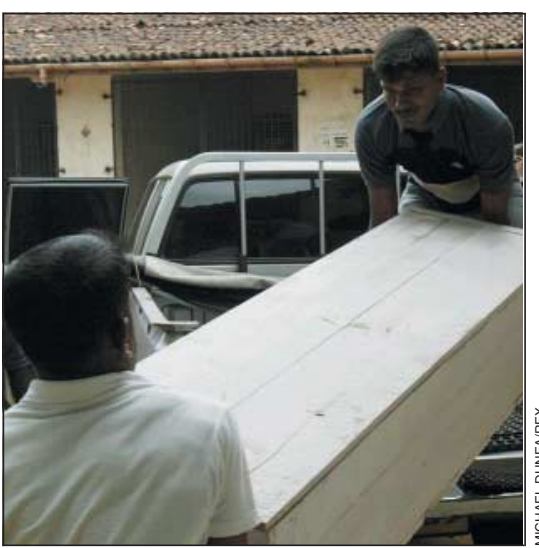

Eighty six $(67 \%)$ dead people arrived from the Middle East during this time, their ages ranging from 20 to $70 ; 47$ were men.

Of the 86 deaths, 42 were related to traumatic injuries. These included 17 road traffic accidents, 4 falls, 2 work related injuries, 13 intentional self harm, 2 assaults (reported as criminal deaths), and 4 of undetermined intent. Thirty one were due to medical causes. Three deaths were without death certificates, and for 10 the cause of death indicated was non-specific. Only the former three deaths were subjected to postmortem examinations in Sri Lanka.

Eighteen of the 47 men $(38 \%)$ were employed as drivers, and 34 of the 39 women $(87 \%)$ as housemaids. The highest proportionate mortality $(\mathrm{n}=34 ; 40 \%)$ was for the housemaids; the drivers ranked second $(\mathrm{n}=18 ; 21 \%)$.

This study highlights several deficiencies in the reporting of causes of death. Non-use of the international form of medical certificate of cause of death is one of them. This format is recommended for national and international purposes since it ensures uniformity and comparability. Next is the lack of proper English translations, with the correct use of medical terms.

Dead people who arrive without a death certificate or a specific cause of death and those reported as criminal deaths are released without further investigation if no request is made by the relatives. This is unsatisfactory as these deaths should at least have an inquest according to the existing laws of Sri Lanka. Action should be initiated promptly and completed in a short time, as delays will discourage the grieving relatives from adhering to the formalities. Any legal costs should be borne by Sri Lanka's government.

D M P Samarakkody public health inspector Health Office, Bandaranayake International Airport, Katunayake, Sri Lanka

Pushpa Jayawardana senior lecturer pushpa@mfac.kln.ac.lk

Chrishantha Abeysena senior lecturer

Department of Community and Family Medicine, Faculty of Medicine, University of Kelaniva,

Ragama, Sri Lanka

Competing interests: None declared.

1 United Nations. General Assembly. Advancement of women. Violence against women migrant workers. http://un.org/ Violence against women migrant workers. http:/
documents/ga/docs/49/planary/a49354.html.

documents/ga/docs/49/planary/a49354.html.
2 Violence against women migrant workers. www.cenwor.lk Violence against women migrant workers. w
migrantwomen.html (accessed 3 Oct 2006).

migrantwomen.html (accessed 3 Oct 2006). 3 International Movement Against All Forms of Discrimination and Racism. Project for women migrant workers in Sri Lanka. www.imadr.org/project/srilanka/srihome.htm (accessed 3 Oct 2006).

4 Priyangika N, Fernando K. Sri Lankan government fails to investigate deaths of migrant workers. wwwwsws.org articles/2004/jan2004/srme-j13.shtml (accessed 3 Oct 2006)

5 Country Profile: Sri Lanka. http://home.pacific.net.hk $\sim$ amc/papers/AMY98SL.htm (accessed 3 Oct 2006).

\section{Child labour in Arab} countries: call for action

Editor-A PubMed search not limited by year and using the terms "child labour", "child labor", and "working children" found a total of nine peer reviewed studies on working children in Arab countries (Lebanon 3, Jordan 3, Egypt 2, and Morocco 1). Some might attribute this to the seemingly less devastating conditions of child labour in the Middle East and North Africa compared with other developing countries. ${ }^{1}$ We argue otherwise, using our experience in Lebanon.

Children in Lebanon and most Arab countries are often employed in small hazardous industries, including artisan production, trades and service, in the agricultural sector, and in homes as domestic helpers. Such workplaces are assumed to be less hazardous to the health of working children than major industries, especially if owned by a family member or a friend. However, children in artisan and mechanics shops work under poor sanitary conditions with almost non-existent engineering or personal protective measures, and suffer from physical strain, long hours of work, low wages, and high exposure to noise and chemicals. ${ }^{2}$ When their health was compared with that of non-working school children, differences were not striking. ${ }^{3}$ However, notable differences were identified when subclinical neurotoxic effects of solvents were investigated. ${ }^{45}$

Working children in mechanic and artisan shops are exposed to solvents at 


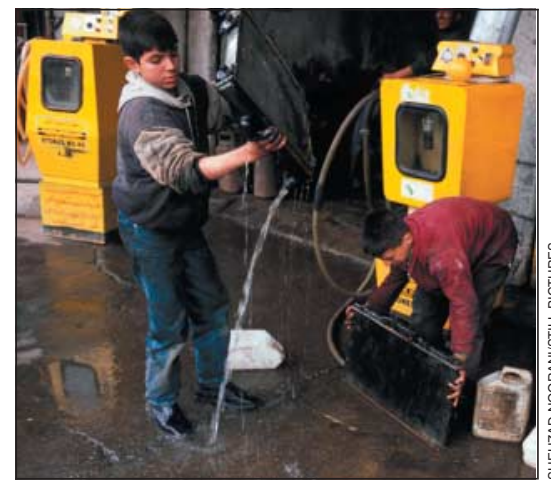

much higher air concentrations than allowable exposure limits for adults, not accounting for dermal exposure in a population that uses solvents to degrease contaminated hands. ${ }^{2}$ Compared with schoolchildren and working children not exposed to solvents, working children exposed to solvents performed worse on most neurophysiological and neurobehavioural tests. $^{45}$ Whether these effects are reversible, permanent, or will worsen with further exposure is unknown, as is the long term effect on children's employment and productivity.

The magnitude of hazards to which working children, including those in Arab countries, are exposed must not be underestimated and may increase with the rising political and economic unrest in the region and the violent conflicts in Lebanon, Iraq, and Palestine. We recommend that more studies on child labour be conducted, especially cohort studies on long term health effects and studies on girls.

Basema Saddik lecturer

Faculty of Health Sciences, University of Sydney, PO Box 170, Lidcombe, NSW 1825, Australia b.saddik@fhs.usyd.edu.au

Iman Nuwayhid professor

Department of Environmental Health Faculty of Health Sciences, American University of Beirut Lebanon

Competing interests: None declared.

1 International Programme on the Elimination of Child Labour (IPEC) and Statistical Information and Monitoring Programme on Child Labour (SIMPOC). Every child counts-new global estimates on child labour. Geneva: International Labour Office. 2002. www.ilo.org/public/english/ standards/ipec/simpoc/others/globalest.pdf (accessed 20 Jun 2006).

2 Nuwayhid I, Saddik B, Quba'a R. Working children in small industrial establishments in Tripoli and Akkar-Lebanon: their work environment and work activities. Report submitted to the International Programme for the Elimination of Child Labour (IPEC) at the International Labour Organization, Geneva: International Labour Office, 2001.

3 Nuwayhid I, Usta J, Makarem M, Khudr A, Zein A. Health of children working in small urban industrial shops. Occup Environ Med 2005;62:86-94.

4 Saddik B, Nuwayhid I, Williamson A, Black D. Evidence of neurotoxicity in working children in Lebanon. Neurotoxicology 2003;24:733-9.

5 Saddik B, Williamson A, Nuwayhid I, Black D. The effects of solvent exposure on memory and motor dexterity in working children. Public Health Rep 2005;120:657-63.

\section{Eastern Mediterranean}

\section{Association of Medical Editors}

EdITOR-The Eastern Mediterranean region has more than 400 medical journals in different languages, some of which appear in prestigious international indices. ${ }^{1}$ The region's Index Medicus database provides a current awareness service to what has been published in the region (www.emro.who.int/ HIS/VHSL/Imemr.htm).

In 2003 the WHO regional office for the Eastern Mediterranean hosted in Cairo the first regional conference on medical journals in the area that it serves, one outcome of which was the formation by a group of editors of the Eastern Mediterranean Association of Medical Editors (EMAME). At two subsequent conferences in Riyadh (2004) and Shiraz (2006), EMAME has sought ways to establish more widespread cooperation among editors and to improve the quality of biomedical publication in the region.

EMAME's mission is to support and promote medical journalism in the Eastern Mediterranean region by fostering networking, education, discussion, and exchange of information and knowledge. Editors and previous editors of peer reviewed medical journals in the region are eligible for membership. Apart from regional conferences, members are also connected through an active listserve. EMAME is closely affiliated to the WHO regional office for the Eastern Mediterranean, which hosts the EMAME website (www.emro.who.int/EMAME/) and listserve. The association has five committees dealing with editorship, publishing ethics, education and training, evidence based medicine, and research. The next regional conference will be held in Bahrain in 2008.

Arash Etemadi vice chancellor for research aetemadi@tums.ac.ir

Akbar Fotouhi assistant professor of epidemiology Department of Epidemiology and Biostatistics, School of Public Health, Tehran University of Medical Sciences, Tehran, Iran

Asieh Golozar researcher

Tehran University of Medical Sciences, Tehran, Iran Jane Nicholson editor

World Health Organization, Regional Office for the Eastern Mediterranean, Cairo 11371, Egypt

Competing interests: None declared.

1 Habibzadeh F. A snapshot of medical journals from the Middle East. Lancet 2006;367:978.

\section{Lessons learnt from the front line in Israel}

EDITOR-Over the past six years my pager has accompanied me everywhere. The bleep all too often signals another terror attack. Together with my team, I have managed 49 terror related mass casualty events and cared for over 3000 victims. Although the work is difficult, we try to make the most of our experience. Thus Israeli doctors have written guidelines on management of terror related emergencies, published lessons learnt, ${ }^{1}$ initiated research projects related to terror related injuries, carried out workshops, and given lectures all over the world.

But terror is not merely of professional interest. Every time my pager announces a terrorist attack I wonder whether any of my family has been affected. I often have to work for many hours before I get a message confirming everyone is safe. In the emergency department it is not uncommon to find a captured terrorist in one bed and his victims in the three adjacent gurneys. Who is the team meant to attend to first? Of course, these decisions are dictated solely by the medical priorities, although we sometimes get complaints from the families.

We hope that others will learn from our mistakes. These include, for example, depending solely on the mobile telephone system (which often collapses because of overload in an emergency), establishing a public information centre too close to the emergency department, and underestimating the severe mental and physical stress on all staff (we now offer psychological counselling and external stress relief activities).

The most important lesson has been that the best investment is in good quality preparation for terrorist related emergencies. We have a detailed manual for each type of potential threat-conventional, chemical, biological, radiological, or cyber. ${ }^{2}$ Staff are instructed both in the care of various terror related injuries and in the administrative aspects of these emergencies. Relevant staff are given treatment cards and checklists for non-conventional injuries. Good team work and robust methods of communications, which are both crucial, are emphasised. Minimal structural modifications (such as establishing oxygen pipes in improvised admission areas) and maintaining adequate supplies are essential. ${ }^{4}$

We constantly strive for quicker, more efficient ways to save life and limb. Both the operation and coordination of the emergency plans are regularly re-evaluated and tested by full scale drills with simulated casualties. ${ }^{5}$ Our hospital, as well as all others in Israel, goes through this process twice a year, under the supervision of the Department of Emergency Services of the Ministry of Health. Although in this kind of chaos practice never makes perfect, it does allow us to be as effective as circumstances allow.

Shmuel C Shapira Director, Hebrew University-Hadassah School of Public Health Hadassah University Hospital and Hebrew University School of Medicine and Public Health, POB 12000 Jerusalem, Israel 91120 sshapira@hadassah.org.il

I thank Mark Clarfield for his helpful comments. Competing interests: None declared.

1 Sheffy N, Mintz YP, Rivkind AI, Shapira SC. Terror related

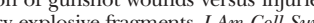
2006;203:297-303.

JV Fitzgerald M, Kossman T, Joseph A, Pearce A, Tenfeld JV, Fizgerald M, Kossman T, Joseph A, Pearce A, Tan G, et al. Ts the Australian hospital system adequa Prepar SC, Shem J Med Aust 2005; 183.567-70. (terroris

4 Shapira SC, Mor-Yosef S. Applying lessons from medical Shapira SC, Mor-Yosef S. Applying lessons from medica management of conventional terror to responding . Cofit ON, Leibovi D, Stem J, Henig A, Shapia SC. The " J, Henig A, Shapira SC. The efficacy of integrating "smart simulated casualties" in

More letters are available on bmi.com 